\title{
Plasma Actin, Gelsolin and Orosomucoid Levels after Eccentric Exercise
}

\author{
by \\ Éva Tékus ${ }^{1,2}$, Márk Váczi ${ }^{1}$ Zoltán Horváth-Szalai ${ }^{3}$, Andrea Ludány³, \\ Tamás Kőszegi ${ }^{3,4}$, Márta Wilhelm ${ }^{1}$
}

\begin{abstract}
The present study investigated the acute effect of eccentric exercise on blood plasma actin, gelsolin (GSN) and orosomucoid (AGP) levels in untrained and moderately trained individuals, and their correlation with exercise induced muscle damage (EIMD) markers (CK, intensity of muscle soreness and maximal voluntary contraction torque deficit). Healthy physical education students (6 untrained, 12 moderately trained) participated in this research. Actin, GSN, AGP and CK levels were measured in blood plasma at baseline, immediately, $1 \mathrm{~h}, 6 \mathrm{~h}$ and $24 \mathrm{~h}$ post-exercise comprising 90 eccentric quadriceps contractions performed on a dynamometer. There was significant time main effect for GSN, AGP, CK and significant difference was found between baseline and the lowest value of post-exercise GSN ( $p<0.05)$, as well as baseline and the highest value of post-exercise AGP $(p<0.05)$. Relationships were found between GSN levels and other indirect EIMD markers (between all GSN levels at post-exercise and CK activity at $6 h, p<0.05$; GSNMIN and muscle soreness at post-exercise, $p<0.04), G S N$ and AGP; however, actin did not correlate at any time points with GSN. Actin, GSN, AGP and CK responses after eccentric exercise do not seem sensitive to training status. The plasma actin level is used as an indicator of injury, however, our results suggest that it is not an accurate marker of EIMD, while plasma GSN concentrations show a better relationship with EIMD and the post-exercise inflammatory process. The elevated plasma AGP and the correlation between GSN and AGP seem to be promising for assessment of exerciseinduced muscle injury.
\end{abstract}

Key words: eccentric exercise, muscle damage, biomarker, actin, gelsolin, exercise

\section{Introduction}

Exercise-induced muscle damage (EIMD) in striated muscle might lead to major injuries, like hamstring tears (Brockett et al., 2001). Predominantly the active lengthening of the muscle (eccentric contraction) can cause disruptions of the sarcomeres as well as other parts of the muscle cells (cell membrane, sarcoplasmic reticulum, T-tubes) (Proske and Morgan, 2001).

Numerous indirect markers such as contractile proteins (like myosin heavy chain;
Sorichter et al., 2001), isoenzymes, creatine kinase (CK; Stäubli et al., 1985), myoglobin (Munjal et al., 1983; Speranza et al., 1997), aldolase (Kanda et al., 2014), aspartate amino transferase (Lippi et al., 2008; Van der Meulen et al., 1991) and lactate dehydrogenase (Munjal et al., 1983) have been used to quantify EIMD. Highly sensitive protein analytical techniques made it possible to measure several other marker molecules (skeletal troponin I, Sorichter et al., 1997; fast skeletal troponin I, Chapman et al., 2013; $\alpha$-actin, Martinez-Amat et

\footnotetext{
1 - Institute of Sport Sciences and Physical Education, University of Pécs, Pécs, Hungary.

2 - Doctoral School of Biology and Sportbiology, University of Pécs, Pécs, Hungary.

3 - Institute of Laboratory Medicine, University of Pécs, Pécs, Hungary.

4 - János Szentágothai Research Center, Pécs, Hungary.
} 
al., 2005; oxidative stress markers, Bouzid et al., 2014) after intensive exercise.

Martinez-Amat et al. (2005) measured abnormally high serum $\alpha$-actin concentration in patients with severe skeletal muscle trauma immediately after admission to the hospital. Later, Amat et al. (2007) found higher $\alpha$-actin levels in athletes with skeletal muscle lesions versus healthy athletes, suggesting that $\alpha$-actin concentration might be sensitive to EIMD in athletes. In contrast, Féasson et al. (2002) reported that the amount of $\alpha$-actin remained unchanged immediately, 1 and 14 days after downhill treadmill running. Due to these contradictory data and the lack of correlation analysis with other conventional markers, it remains unknown whether plasma concentration of $\alpha$-actin is suitable for monitoring EIMD.

After severe skeletal muscle injuries, a large amount of actin might be released into the blood from dead or dying cells and during this process $\mathrm{Ca} 2+$ activated plasma gelsolin (GSN) severs and removes actin filaments to prevent the toxicity of F-actin (Haddad et al., 1990). In numerous acute and chronic diseases (sepsis, prolonged hypoxia, malaria) GSN levels decrease, presumably having an important role in the cellular inflammatory response (Bucki et al., 2008). In contrast, serum GSN was found to be elevated for 7-11 days after acute rhabdomyolysis in five patients (Löfberg et al., 1998). In a bicycle ergometer test, the untrained controls' plasma GSN level decreased, while in athletes it increased for 30 minutes after exercise (Yu et al., 2013), suggesting that endurance exercise changes the expression of gelsolin in striated muscle.

Orosomucoid $(\alpha-1$ acid glycoprotein, AGP) is a member of the lipocalin plasma glycoprotein family and the level of this molecule increases during acute phase reactions (Gornik and Lauc, 2008). It has been proposed that AGP is a natural anti-inflammatory and immunemodulatory agent (Fournier et al., 2000), suggesting that it might be sensitive to EIMD. Poortmans and Haralambie (1979) found that immediately after a $100 \mathrm{~km}$ run the resting serum AGP level decreased while $24 \mathrm{~h}$ later it increased significantly.

Besides quantification of blood parameters, delayed onset muscle soreness (DOMS), the muscle stiffness scale (Hody et al.,
2013; Nosaka and Sakamoto, 2001) and MVC torque (Nosaka and Sakamoto, 2001) have been used to estimate EIMD by many researchers, although, according to Nosaka et al. (2002), DOMS is a poor indicator of EIMD.

Unfortunately, only few indirect markers possess high sensitivity and specificity in estimation of EIMD and researchers reported high response variations in the conventional markers (McKune et al., 2012), although it would be important to identify molecules to accurately monitor the damage and the recovery processes after intense exercise. Our knowledge is limited to the aforementioned molecules and their relationship to eccentric exercise.

The acute response after eccentric exercise (changes in levels of muscle damage indicators) depends on training status (Baird et al., 2012; Vincent and Vincent, 1997), however, in most studies researchers were unable to identify specific damage markers (Brancaccio et al., 2007; McKune et al., 2012). After exercise, CK activity of trained subjects was lower than in healthy controls (Brancaccio et al., 2007). Therefore, it is plausible to hypothesize that muscle- and inflammatory molecules could sensitively characterize groups with a different fitness level.

Considering the uncertainties in assessment of muscle injury, the aim of the present study was to investigate (i) the acute effect of eccentric exercise on the time course of changes of blood plasma CK, actin, GSN and AGP levels in humans, and (ii) to investigate whether these proposed markers would correlate with indirect EIMD markers (plasma CK activity, DOMS, MVC torque deficit).

\section{Material and Methods}

\section{Participants and procedures}

Eighteen healthy males were recruited for this research: untrained, $(n=6$; age $=24.7 \pm 2.9$ years), who had not been involved in regular training for years, and moderately trained $(\mathrm{n}=12$; $23.3 \pm 2.1$ years), who were physical education students, but did not participate in any competitive sports. The moderately trained subjects performed physical activity at least 8 hours per week. Subjects were requested to avoid any strenuous and unusual exercise one week prior to and during the experiment.

Subjects were given verbal and written 
information about the experiment and they signed an informed consent form to participate in the study, which was approved by the Ethics Committee of the University of Pécs in accordance with the Declaration of Helsinki (1975).

Body height, mass and body mass index of the subjects were measured. Body composition was estimated by bioelectrical impedance analysis (Tanita BC-20MA; Tanita, Tokyo, Japan).

Indirect muscle damage indicators (plasma CK, actin), plasma GSN and AGP levels were measured pre- (baseline), immediately $(0 \mathrm{~h})$, $1 \mathrm{~h}, 6 \mathrm{~h}$ and $24 \mathrm{~h}$ post-exercise comprising eccentric quadriceps contractions performed on a dynamometer. The time points of blood sample collections were determined based on previous experiments (Sorichter et al., 1997; Stäubli et al., 1985). Quadriceps MVC torque was measured at baseline and $24 \mathrm{~h}$ post-exercise, and the difference expressed in $\mathrm{N} \cdot \mathrm{m}$ was considered as the torque deficit.

The subjective intensity of soreness, as an indirect marker of muscle damage, was estimated using a visual analog soreness scale (0 without pain to 10 with intolerable pain) at baseline and 24 $\mathrm{h}$ post-exercise (Bobbert et al., 1986).

\section{Blood sampling and analyses}

Venous blood samples were taken using EDTA-containing Vacutainer tubes (Becton Dickinson) and then centrifuged at $1500 \mathrm{~g}$ for 10 min. Plasma aliquots in $1.5 \mathrm{ml}$ Eppendorf tubes were stored at $-70^{\circ} \mathrm{C}$ until analyses.

For CK activity measurement, a kinetic optimized UV test was used in our accredited routine clinical laboratory (Department of Laboratory Medicine, University of Pécs) by an automated clinical chemistry analyzer (Cobas Integra 400 Plus, Roche Diagnostics, Hungary) with the interassay precision of less than $7 \%$ coefficient of variation. Plasma concentrations of actin, GSN and AGP were determined by Western blot technique with enhanced chemiluminescence detection. Serial dilutions of purified rabbit skeletal muscle actin and GSN expressed in E. coli (gift of the Department of Biophysics, our University) and AGP standards (OPJD03 N FLC Standard, Siemens) were used for calibration. Plasma sample of the same subject was applied in every gel as an internal standard. SDS PAGE $(10 \%)$ was used by Laemmli in a Mini Protean III apparatus (Bio-Rad, Hercules, California, USA).
After electrophoresis, gels were transferred to nitrocellulose membranes at 150 $\mathrm{mA}$ for $20 \mathrm{~min}$ at room temperature (semi-dry method, NovaBlot, Pharmacia). Membranes were blocked in a solution containing $50 \mathrm{mM}$ Tris/ $/ \mathrm{HCl}$, $150 \mathrm{mM} \mathrm{NaCl}, 5 \%$ non-fat skimmed milk (BioRad), $0.1 \%$ Tween-20, pH 7.6 at $4^{\circ} \mathrm{C}$ overnight. The membranes for actin detection were reacted with rabbit anti-actin antibody (N-terminal, Sigma-Aldrich, A2103, 1:1000), while the parallel membranes were treated with a mixture of rabbit anti-human GSN (DakoCytomation, A014601, 1:1000) and rabbit anti-human AGP antibody (Q032605, DakoCytomation, 1:400) all diluted in the blocking solution and incubated at $37^{\circ} \mathrm{C}$ for 1 h. After 5 washings with Tris buffered saline containing $0.05 \%$ Tween (TBST), the membranes were incubated with the secondary antibody (horseradish peroxidase-conjugated goat antirabbit immunoglobulins at 1:5000 dilution in the blocking solution, DakoCytomation, P044801) for $1 \mathrm{~h}$ at $37^{\circ} \mathrm{C}$ with consecutive 4 washings as previously described. The last washing (for 10 min) was with TBS without Tween. For actin detection a femtogram sensitivity reagent was used (Thermo Scientific), while for simultaneous GSN and AGP quantification a homemade reagent with 4-iodophenol enhancer and luminol$\mathrm{H}_{2} \mathrm{O}_{2}$ was applied. The blots were photographed in a G:BOX Chemi XX6 gel documentation system (Syngene) and quantified by its densitometric software. The absolute protein contents of the internal standards were determined using the calibration curve computed from the signals of the serial dilutions of the calibrators. The protein contents of the unknowns were calculated from the determined concentration of the internal standards, taking into account the total dilutions of the plasma samples.

In the post-exercise blood measurements, the lowest (MIN) and the highest values (MAX) were also measured for every subject and used for further analysis.

\section{Quadriceps MVC torque}

MVC was measured in a seated position on a Multicont II isokinetic device (Mediagnost and Mechatronic Ltd., Hungary). Subjects performed three maximal isometric contractions with the trained quadriceps at the $70^{\circ}$ knee angle, which was within the range of the optimal knee angles reported by others (Becker and Awiszus, 
2001; Brughelly et al., 2010). The highest torque value of the three trials was used for further analysis (Váczi et al., 2014).

\section{Eccentric exercise}

After a 5 min aerobic warm-up on a cycle ergometer (Ergoline 900, Ergometrics, Germany) and 5 min stretching of the knee extensors and hip flexors, all subjects performed 6 sets of 15 repetitions of maximal eccentric quadriceps contractions with the dominant limb on the same dynamometer (Multicont II, Mediagnost and Mechatronic Ltd., Hungary; Váczi et al., 2009). The contractions were executed between 20 and $80^{\circ}$ knee angles, at $60^{\circ} \cdot \mathrm{s}^{-1}$ constant angular velocity, and one minute rest was provided between following sets. All subjects performed various extent of mechanical work during the 90 contractions, which were calculated for every subject.

\section{Statistical Analyses}

To evaluate the normality of the data, the Shapiro-Wilk test was used. Each variable showed normal distribution, therefore the time-course of changes in the EIMD markers across groups was compared with a two-way (group by time) repeated measures analysis of variance (ANOVA). One-way repeated measures ANOVA tests were used with Bonferroni post-hoc analyses to investigate the differences among the five measurement times, as well as MIN and MAX when significant time-main effect was detected. The relationships between the measured variables were examined with the Pearson correlation test. The anthropometric data were compared between groups using independent samples t-tests. Values are reported as mean \pm SEM (standard error of the mean). The level of significance was set at $p<0.05$.

\section{Results}

Anthropometric variables of the subjects are summarized in Table 1 . There were significant differences between the body fat percentage and fat mass of moderately trained and untrained subjects, but other characteristics of body composition did not differ. Weekly training volume ( $p=0.0001$; Table 1$)$, the value of total work performed during the eccentric exercise $(p=$ $0.023)$ and the baseline MVC torque ( $p=0.037$; Table 2) were significantly higher in the trained group.

There was no significant group-by-time interaction in plasma actin, GSN, AGP and CK levels, suggesting that changes in time were similar in the two groups. However, we found significant time main effect for the aforementioned blood markers, suggesting that they changed significantly over time regardless of the training status.

Plasma actin levels did not show substantial differences between groups throughout the study period (Figure 1a). The post-hoc analyses revealed that the actin level elevated significantly from $0 \mathrm{~h}$ to $1 \mathrm{~h}$.

GSN levels peaked immediately after exercise and gradually decreased thereafter (Figure 1b). According to the post-hoc analyses, the MIN values significantly differed from the resting GSN concentration $(p<0.05)$.

There were significant differences between AGP MAX and the baseline value, as well as between 1, $6 \mathrm{~h}$ post-exercise and MAX (Figure 1c).

CK activity continuously increased postexercise and peaked at $24 \mathrm{~h}$ (Figure 1d). The posthoc analyses revealed significant differences between the baseline and $24 \mathrm{~h}$ post-exercise CK levels.

The baseline MVC torque was significantly higher than at $24 \mathrm{~h}(p<0.05)$.

Since no group by time interaction was found in any of the measured variables, for the Pearson correlation test, the moderately trained and untrained groups were combined. Relationships between plasma actin, GSN, AGP and conventional muscle damage markers (muscle soreness score, CK, torque deficit) obtained at each time points and the MIN and MAX values were also considered investigating the relationship of the measured variables (Table 3).

No relationship was found between plasma actin and GSN concentrations at any time points, but actin levels significantly correlated with the AGP levels $24 \mathrm{~h}$ post-exercise $(\mathrm{r}=-0.551$; $p<0.05)$. The resting level of GSN negatively correlated with AGP immediately after and $1 \mathrm{~h}$ post-exercise $(\mathrm{r}=-0.591 ; \mathrm{r}=-0.517 ; p<0.05)$. The total quadriceps mechanical work correlated with the GSN level at $6 \mathrm{~h}$ and $24 \mathrm{~h}$ post-exercise and MIN $(r=0.484 ; r=0.517 ; r=0.499 ; p<0.05)$. 


\begin{tabular}{|c|c|c|c|c|c|c|c|c|}
\hline & & & & & \multicolumn{4}{|c|}{ Table 1} \\
\hline \multicolumn{9}{|c|}{ Anthropometric characteristics of the experimental groups. } \\
\hline & $\begin{array}{l}\text { Age } \\
\text { (yrs) }\end{array}$ & $\begin{array}{c}\text { Body } \\
\text { mass } \\
(\mathrm{kg})\end{array}$ & $\begin{array}{l}\text { Body } \\
\text { height } \\
(\mathrm{cm})\end{array}$ & $\begin{array}{l}\mathrm{BMI} \\
(\mathrm{kg} \cdot \\
\left.\mathrm{m}^{-2}\right)\end{array}$ & $\begin{array}{c}\text { Body fat } \\
\text { percentage } \\
(\%)\end{array}$ & $\begin{array}{c}\text { Fat mass } \\
(\mathrm{kg})\end{array}$ & $\begin{array}{l}\text { Fat-free } \\
\text { mass }(k g)\end{array}$ & $\begin{array}{l}\text { Training } \\
\text { volume } \\
\text { (hours } \\
\text {. } \\
\text { week }^{-1} \text { ) }\end{array}$ \\
\hline $\begin{array}{l}\text { Moderately } \\
\text { trained } \\
\text { group } n=12\end{array}$ & $\begin{array}{c}23.31 \pm \\
2.10\end{array}$ & $\begin{array}{c}77.98 \pm \\
10.05\end{array}$ & $\begin{array}{c}181.88 \pm \\
8.50\end{array}$ & $\begin{array}{c}23.56 \pm \\
2.46\end{array}$ & $\begin{array}{l}10.09 \pm \\
3.91^{* *}\end{array}$ & $\begin{array}{l}8.28 \pm \\
3.50^{* *}\end{array}$ & $\begin{array}{c}69.70 \pm \\
2.86\end{array}$ & $\begin{array}{c}10.20 \pm \\
1.87^{* *}\end{array}$ \\
\hline $\begin{array}{c}\text { Untrained } \\
\text { group } \\
n=6\end{array}$ & $\begin{array}{c}24.67 \pm \\
2.88\end{array}$ & $\begin{array}{c}85.13 \pm \\
12.86\end{array}$ & $\begin{array}{c}178.17 \pm \\
5.23\end{array}$ & $\begin{array}{c}26.90 \pm \\
4.69\end{array}$ & $\begin{array}{c}18.45 \pm \\
6.42\end{array}$ & $\begin{array}{c}16.45 \pm \\
6.97\end{array}$ & $\begin{array}{c}68.68 \pm \\
3.01\end{array}$ & $\begin{array}{c}0.00 \pm \\
0.00\end{array}$ \\
\hline
\end{tabular}

\begin{tabular}{|c|c|c|c|c|}
\hline \multicolumn{5}{|c|}{ Table 2} \\
\hline \multicolumn{5}{|c|}{ MVC torque and muscle soreness of the experimental groups. } \\
\hline & \multicolumn{2}{|c|}{ Moderately trained } & \multicolumn{2}{|c|}{ Untrained } \\
\hline & Baseline & 24h post-exercise & Baseline & $24 \mathrm{~h}$ post-exercise \\
\hline MVC torque $(\mathrm{N} \bullet \mathrm{m})$ & $302.43 \pm 14.15^{*}$ & $274.85 \pm 22.61$ & $252.83 \pm 11.37$ & $218.00 \pm 19.39$ \\
\hline $\begin{array}{c}\text { Muscle soreness } \\
\text { score }\end{array}$ & $0.42 \pm 0.19$ & $3.23 \pm 0.74$ & $0.67 \pm 0.33$ & $3.83 \pm 1.91$ \\
\hline \multicolumn{5}{|c|}{ Data are mean \pm SEM. *Significantly different from the untrained group $(p<0.05)$. } \\
\hline
\end{tabular}

\begin{tabular}{|c|c|c|c|c|c|}
\hline \multicolumn{6}{|c|}{$\begin{array}{l}\text { Table } 3 \\
\text { mucoid }\end{array}$} \\
\hline & GSNIP $_{\text {IP }}$ & $\mathrm{GSN}_{6 \mathrm{~h}}$ & $\mathrm{GSN}_{24 \mathrm{~h}}$ & GSNMIN & $\mathrm{AGP}_{24 \mathrm{~h}}$ \\
\hline $\begin{array}{l}\text { Muscle soreness } \\
\text { score (POST) }\end{array}$ & $\begin{array}{c}\mathrm{r}=-0.37 \\
\text { n.s. }\end{array}$ & $\begin{array}{c}\mathrm{r}=-0.47 \\
\text { n.s. }\end{array}$ & $\begin{array}{c}\mathrm{r}=-0.37 \\
\text { n.s. }\end{array}$ & $\begin{array}{l}\mathrm{r}=-0.50 \\
p=0.040\end{array}$ & $\begin{array}{c}r=-0.15 \\
\text { n.s. }\end{array}$ \\
\hline $\begin{array}{l}\text { Muscle soreness } \\
\text { score (DIFF) }\end{array}$ & $\begin{array}{c}\mathrm{r}=-0.34 \\
\text { n.s. }\end{array}$ & $\begin{array}{c}\mathrm{r}=-0.40 \\
\text { n.s. }\end{array}$ & $\begin{array}{c}\mathrm{r}=-0.28 \\
\text { n.s. }\end{array}$ & $\begin{array}{l}\mathrm{r}=-0.49 \\
p=0.046\end{array}$ & $\begin{array}{c}\mathrm{r}=-0.08 \\
\text { n.s. }\end{array}$ \\
\hline $\mathrm{CK}_{6 \mathrm{~h}}$ & $\begin{array}{c}r=0.57 \\
p=0.013\end{array}$ & $\begin{array}{c}\mathrm{r}=0.48 \\
p=0.043\end{array}$ & $\begin{array}{c}\mathrm{r}=0.66 \\
p=0.004\end{array}$ & $\begin{array}{c}\mathrm{r}=0.48 \\
p=0.043\end{array}$ & $\begin{array}{c}\mathrm{r}=0.20 \\
\text { n.s. }\end{array}$ \\
\hline Torque deficit & $\begin{array}{c}\mathrm{r}=-0.38 \\
\text { n.s. }\end{array}$ & $\begin{array}{c}\mathrm{r}=0.21 \\
\text { n.s. }\end{array}$ & $\begin{array}{c}\mathrm{r}=0.20 \\
\text { n.s. }\end{array}$ & $\begin{array}{c}\mathrm{r}=0.30 \\
\text { n.s. }\end{array}$ & $\begin{array}{c}\mathrm{r}=-0.19 \\
\text { n.s. }\end{array}$ \\
\hline $\begin{array}{r}\text { Muscle } \\
\text { Muscle so } \\
(m \imath \\
\text { CK } \\
6 \\
\text { plasma o }\end{array}$ & $\begin{array}{l}\text { reness scor } \\
\text { ness score } \\
\text { cle sorenes } \\
\text { creatine ki } \\
S N_{I P,} 6 h, 24 h \\
4 \text { hours ar } \\
\text { somucoid }\end{array}$ & $\begin{array}{l}\text { ST): } \text { muscl } \\
\text { =) differenc } \\
\text { baseline) a } \\
\text { enzyme a } \\
\text { : plasma } g \\
\text { at minimal } \\
\text { at hou }\end{array}$ & $\begin{array}{l}\text { reness at } \\
\text { etween } M \\
\text { Muscle so } \\
\text { bity at } 6 \text { ho } \\
\text { lin level a } \\
\text { lue post-es } \\
\text { ost-exerci }\end{array}$ & $\begin{array}{l}\text { urs post-e } \\
\text { soreness } \\
\text { ss score }(P C \\
\text { post-exerc } \\
\text { mediately, } \\
\text { se, AGP } \\
b<0.05\end{array}$ & $\begin{array}{l}\text { ise, } \\
\text { (PRE) } \\
0.01\end{array}$ \\
\hline
\end{tabular}



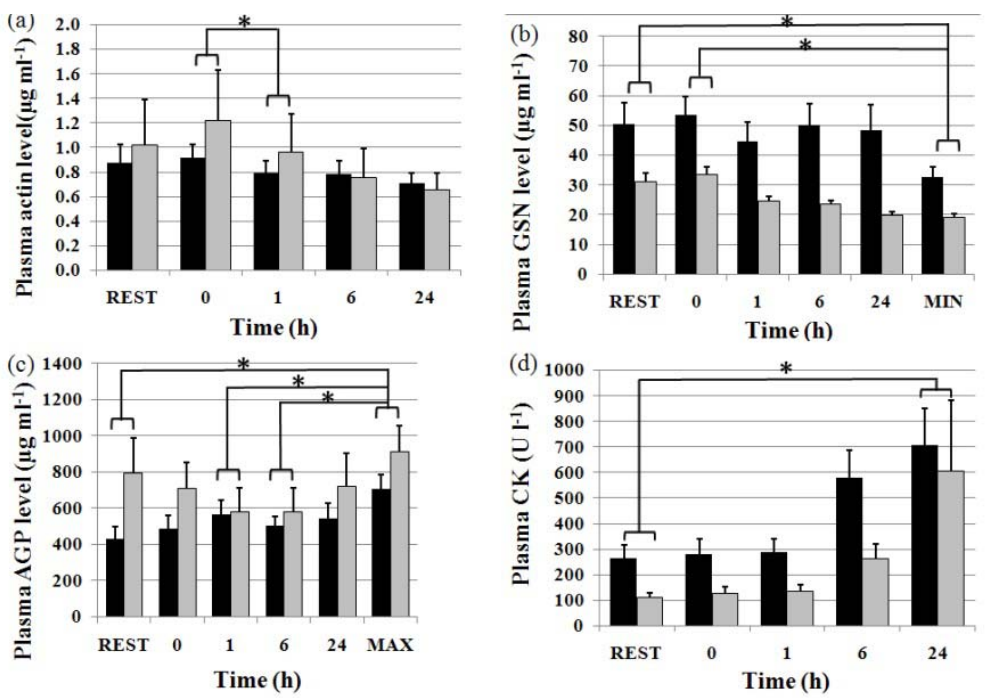

Figure 1

Plasma actin, gelsolin, orosomucoid and CK levels.

Plasma actin (a), gelsolin (GSN, b), orosomucoid $(A G P, c)$ and $C K(d)$ level of moderately trained (black bar) and untrained

(grey bar) groups combined pre-(baseline),

immediately after $(0 \mathrm{~h}), 1 \mathrm{~h}, 6 \mathrm{~h}$ and $24 \mathrm{~h}$ post-exercise is shown.

The MIN (average time: $14.56 \mathrm{~h}$ )

is the lowest value and MAX (average time: $12.53 \mathrm{~h}$ )

is the maximal level post-exercise.

Data are mean \pm SEM. *Significant difference between

the marked time points of the significant $(p<0.05)$ main effect.

\section{Discussion}

Our research focused on the changes of actin, GSN and AGP levels in plasma after 90 maximal eccentric quadriceps contractions and the relationship between these variables and conventional EIMD markers (CK, muscle soreness score) in moderately trained and untrained groups.

\section{Differences between the experimental groups}

In contrast to some research (Brancaccio et al., 2007; Karamizrak et al., 1994; Vincent and Vincent, 1997), findings of the present study do not support the hypothesis that there are differences between moderately trained and untrained groups in changes of plasma indicators like actin, GSN, AGP and CK after eccentric contractions, indicating that this type of exercise has a similar effect in all subjects with different fitness levels.

It has been proposed that changes in EIMD markers depend on the training status of the subjects, though only few studies investigated this factor. Karamizark et al. (1994), for example, demonstrated different CK and LDH elevations in distance runners and cyclists vs. untrained controls after high intensity concentric-based exercise. After an eccentric-based protocol, Vincent and Vincent (1997) found similar strength deficits in experienced weightlifters compared to untrained controls, which is in agreement with our findings. Since the magnitude of muscle tension contributes to the severity of EIMD, the 
baseline strength profile could be one factor that reveals variations in the changes of EIMD markers. If we use baseline MVC torques to characterize and compare the training status of the experimental groups, our untrained group represents $83 \%$ MVC torque of the trained group, which is similar to that reported by Vincent and Vincent $(87 \%$; 1997). However, unlike in our study, they found greater DOMS and smaller CK elevation in the trained group, which was interpreted as a result of adaptation (reduced permeability or/and less damage in membrane) in the weightlifters. In our study, the baseline MVC torques for both experimental groups were lower than for those of Vincent and Vincent (1997), indicating that our subjects were less trained. Various study designs can cause differences in plasma marker level changes. Based on our investigations, plasma actin, GSN, AGP and CK did not prove to be appropriate markers to characterize EIMD in groups with different fitness levels.

\section{Changes of the plasma actin profile}

In the present study, the resting actin concentration did not differ over time for the two groups combined, while the plasma GSN level decreased significantly within $24 \mathrm{~h}$. This is in agreement with the conclusions of Féasson et al. (2002), showing that the actin level did not change immediately and 1 day after eccentric training. Amat et al. (2007) described earlier that only muscle trauma or lesions caused major actin release into the circulation, so it is possible that plasma actin might be useful for the distinction between micro injuries as well as severe muscle damages and lesions. Supporting this idea, we did not detect any relationship between the plasma actin level and CK or the muscle soreness score.

\section{The plasma GSN profile and the relationship} between actin and GSN

It is well known that quantitative changes of the plasma GSN level can be observed in numerous conditions and diseases (Spinardi and Witke, 2007), however, GSN is a novel molecule in sport science studies. Yu et al. (2013) found opposite responses of plasma GSN concentrations in trained (elevated) and untrained subjects (decreased) after $30 \mathrm{~min}$ of bicycle ergometer training. We detected no significant changes in the GSN level during $24 \mathrm{~h}$ after eccentric training between moderately trained and untrained groups, but found differences between MIN values and the resting GSN level among subjects. GSN is an important molecule, removing actin from the plasma and it has a function in the cellular response of inflammation (Buckiet et al., 2008). Interestingly, we did not find any correlation between actin and GSN levels in our study. However, other indirect EIMD markers, like CK and muscle soreness were significantly correlated with plasma GSN concentrations after exercise. Our data suggest that GSN concentration might be influenced by physical exercise and EIMD, however, GSN change in healthy people is not actin-dependent.

In skeletal, cardiac and smooth muscles, there is a large amount of GSN mRNA and skeletal muscle is the major store of plasma GSN (Kwiatkowski et al., 1988), raising the question how exercise influences GSN release from its stores.

The changes of plasma AGP and CK profile postexercise

In humans, AGP is an acute phase protein with elevation kinetics of 12-24 h after injury and many diseases are associated with the AGP level increase and glycosylation changes (Gornik and Lauc, 2008). Moderate or vigorous physical activity can reduce the resting level of numerous inflammatory mediators (Nimmo et al., 2013).

In this study, the same plasma AGP response was found as Poortmans and Haralambie (1979) described in trained subjects. AGP levels (MAX) peaked within $24 \mathrm{~h}$. The relationship between muscle soreness score difference and the AGP level $24 \mathrm{~h}$ post-exercise suggests that indeed, AGP concentration is related to the extent of exercise induced damage and inflammation.

An inflammatory process has an impact on plasma GSN changes, as it was described in many diseases (Spinardi and Witke, 2007). In our study, the post-exercise GSN MIN value positively correlated with the AGP level immediately and $1 \mathrm{~h}$ post-exercise. Supposedly, the EIMD caused inflammation influenced plasma GSN and AGP levels after exercise.

GSN might be used as a new therapeutic target in different diseases with a reduced GSN level (Spinardi and Witke, 2007). Hypothetically, GSN injection might be a new treatment to prevent secondary tissue injury in patients (Bucki 
et al., 2008) and athletes as well. GSN with its antiinflammatory and actin removing effect could be a remarkable target in the treatment of striated muscle trauma.

Like in other studies after eccentric exercise, plasma CK activity (Stäubli et al., 1985), as a non-specific marker of EIMD (Brancaccio et al., 2007, 2010), reached the maximal value at $24 \mathrm{~h}$, $48 \mathrm{~h}, 96 \mathrm{~h}$ after training (Kanda et al., 2014; Pliauga et al., 2015) or during exertion in the ultra-marathon runners (Jastrzebski et al., 2015).

\section{Correlations between conventional EIMD markers, plasma actin, GSN and AGP}

This is the first study investigating the correlation between some indirect EIMD markers and plasma actin, GSN and AGP concentrations. Chapman et al. (2008) found a low or even no relationship between muscle strength, plasma $\mathrm{CK}$, DOMS, total work and MVC torque. DOMS correlates with CK enzyme activity (Tiidus and Ianuzzo, 1983), however, it showed a weaker correlation between force or myoglobin concentrations (Rodenburg et al., 1993). Löfberg et al. (1998) investigating patients with acute rhabdomyolysis, which is an acute destruction of skeletal muscle, found a negative correlation between peak plasma GSN and peak plasma CK concentrations which is similar to our results.

Plasma actin, GSN AGP and CK are not appropriate markers to characterize EIMD in groups with different fitness levels. Our research has a limitation, since the fitness level of the experimental groups was not measured before eccentric exercise, therefore, we strongly suggest determining the exact strength profile or fitness level of subjects prior to similar study designs as these results are highly influenced by the changes of plasma EIMD markers among different study groups.

In conclusion, further studies should be performed to investigate the plasma actin level as an indicator of the type and extent of injury. Our data and previous research suggest that it is an inappropriate marker of EIMD, however, plasma GSN concentrations show significant relationships with indicators of EIMD and the inflammatory process in striated muscles after exercise. This may explain the elevated plasma AGP level and the correlation between GSN and AGP concentrations.

\section{Acknowledgements}

This work was supported by the Hungarian Society of Sport Science, the European Union and the State of Hungary, co-financed by the European Social Fund in the framework of GINOP-2.3.2. and the Grant of University of Pécs (KA-2016-04). The authors thank the laboratory staff of the Institute of Laboratory Medicine at the University of Pécs for their contribution in blood analyses.

The present scientific contribution is dedicated to the 650th anniversary of the foundation of the University of Pécs, Hungary.

\section{References}

Amat AM, Corrales JAM, Serrano FR, Boulaiz H, Salazar JCP, Contreras FH, Perez OC, Delgado EC, Martin I, Jimenez AA. Role of $\alpha$-actin in muscle damage of injured athletes in comparison with traditional markers. Br J Sports Med, 2007; 41(7): 442-446

Baird MF, Graham SM, Baker JS, Bickerstaff GF. Creatine-kinase- and exercise-related muscle damage implications for muscle performance and recovery. J Nutr Metab, 2012; 2012: 960363

Becker R, Awiszus F. Physiological alterations of maximal voluntary quadriceps activation by changes of knee joint angle. Muscle Nerve, 2001; 24(5): 667-72

Bobbert MF, Hollander AP, Huijing PA. Factors in delayed onset muscle soreness of man. Med Sci Sports Exerc, 1986; 18: 75-81

Bouzid MA, Hammouda O, Matran R, Robin S, Fabre C. Changes in oxidative stress markers and biological markers of muscle injury with aging at rest and in response to an exhaustive exercise. PloS One, 2014; 48(6): 757-67 
Brancaccio P, Lippi G, Maffulli N. Biochemical markers of muscular damage. Clin Chem Lab Med, 2010; 48(6): 757-67

Brancaccio P, Maffulli N, Limongelli FM. Creatine kinase monitoring in sport medicine. Br Med Bull, 2007; 81,82: 209-230

Brockett CL, Morgan DL, Proske U. Human hamstring muscles adapt to eccentric exercise by changing optimum length. Med Sci Sports Exerc, 2001; 33: 783-790

Brughelly M, Cronin J, Nosaka K. Muscle architecture and optimum angle of the knee flexors and extensors: a comparison between cyclists and Australian Rules football players. J Strength Cond Res, 2010; 24(3): 717-721

Bucki R, Levental I, Kulakowska A, Janmey PA. Plasma Gelsolin: Function, prognostic value, and potential therapeutic use. Curr Protein Pept Sci, 2008; 9(6): 541-51

Chapman DW, Newton MJ, Zainuddin Z, Sacco P, Nosaka K. Work and peak torque during eccentric exercise do not predict changes in markers of muscle damage. Br J Sports Med, 2008; 42: 585-591

Chapman DW, Simpson JA, Iscoe S, Robins T, Nosaka K. Changes in serum fast and slow skeletal troponin I concentration following maximal eccentric contractions. J Sci Med Sport, 2013; 16(1): 82-5

Féasson L, Stockholm D, Freyssenet D, Richard I, Duguez S, Beckmann JS, Denis C. Molecular adaptations of neuromuscular disease-associated proteins in response to eccentric exercise in human skeletal muscle. J Physiol, 2002; 543(Pt 1): 297-306

Fournier T, Medjoubi-N N, Porquet D. Alpha-1-acid glycoprotein. Biochim Biophys Acta, 2000; 1482(1-2): 15771

Gornik O, Lauc G. Glycosylation of serum proteins in inflammatory diseases. Dis Markers, 2008; 25(4-5): 26778

Haddad JG, Harper KD, Guoth M, Pietra GG, Sanger JW. Angiopathic consequences of saturating the plasma scavenger system for actin. Proc Natl Acad Sci, 1990; 87(4): 1381-5

Hody S, Rogister B, Leprince P, Wang F, Croisier J-L. Muscle fatigue experienced during maximal eccentric exercise is predictive of the plasma creatine kinase (CK) response. Scand J Med Sci Sports, 2013; 23: 501507

Jastrzebski Z, Zychowska M, Radziminski L, Konieczna A, Kortas J. Damage to liver and skeletal muscles in marathon runners during a $100 \mathrm{~km}$ run with regard to age and running speed. J Hum Kinet, 2015; 45: 93-102

Kanda K, Sugama K, Sakuma J, Kawakami Y, Suzuki K. Evaluation of serum leaking enzymes and investigation into new biomarkers for exercise-induced muscle damage. Exerc Immunol Rev, 2014; 20: 39-54

Karamizrak SO, Ergen E, Tore IR, Akgun N. Changes in serum creatine kinase, lactate dehydrogenase and aldolase activities following supramaximal exercise in athletes. J Sports Med Phys Fitness, 1994; 34: 141146

Kwiatkowski DJ, Mehl R, Izumo S, Nadal-Ginard B, Yin HL. Muscle is the major source of plasma gelsolin. J Biol Chem, 1988; 263(17): 8239-43

Lippi G, Schena F, Salvagno GL, Montagnana M, Gelati M, Tarperi C, Banfi G, Guidi GC. Acute variation of biochemical markers of muscle damage following a 21-km, half-marathon run. Scand J Clin Lab Invest, 2008; 68(7): 667-72

Löfberg M, Paunio T, Tähtelä R, Kiuru S, Somer H. Serum gelsolin and rhabdomyolysis. J Neurol Sci, 1998; 157(2): 187-90

Martinez-Amat A, Boulaiz H, Prados J, Marchal J, Puche PP, Caba O, Rodriguez-Serrano F, Aranega A. Release of $\alpha$-actin into serum after skeletal muscle damage. Br J Sports Med, 2005; 39: 830-834

McKune AJ, Semple SJ, Peters-Futre EM. Acute exercise-induced muscle injury. Biol Sport, 2012; 29: 3-10

Munjal DD, McFadden JA, Matrix PA, Coffman KD, Cattaneo SM. Changes in serum myoglobin, total creatine kinase, lactate dehydrogenase and creatine kinase MB levels in runners. Clin Biochem, 1983; 16(3): 195-9

Nimmo MA, Leggate M, Viana JL, King JA. The effect of physical activity on mediators of inflammation. Diabetes Obes Metab, 2013; 15(Suppl 3): 51-60 
Nosaka K, Newton M, Sacco P. Delayed-onset muscle soreness does not reflect the magnitude of eccentric exercise-induced muscle damage. Scand J Med Sci Sports, 2002; 12: 337-346

Nosaka K, Sakamoto K. Effect of elbow joint angle on the magnitude of muscle damage to the elbow flexors. Med Sci Sports Exerc, 2001; 33(1): 22-29

Pliauga V, Kamandulis S, Dargevičiūtė G, Jaszczanin J, Klizienè I, Stanislovaitienė J, Stanislovaitis A. The effect of a simulated basketball game on players' sprint and jump performance, temperature and muscle damage. J Hum Kinet, 2015; 46: 167-175

Poortmans JR, Haralambie G. Biochemical changes in a $100 \mathrm{~km}$ run: proteins in serum and urine. Eur J Appl Physiol, 1979; 40: 245-54

Proske U, Morgan DL. Muscle damage from eccentric exercise: mechanical signs, adaptation and clinical applications. J Physiol, 2001; 537: 333-45

Rodenburg JB, Bar PR, De Boer RW. Relations between muscle soreness and biochemical and functional outcomes of eccentric exercise. J Appl Physiol, 1993; 74(6): 2976-83

Sorichter S, Mair J, Koller A, Gebert W, Rama D, Calzolari C, Artner-Dworzak E, Puschendorf B. Skeletal troponin I as a marker of exercise-induced muscle damage. J Appl Physiol, 1997; 83(4): 1076-1082

Sorichter S, Mair J, Koller A, Müller E, Kremser C, Judmaier W, Haid C, Calzolari C, Puschendorf B. Creatine kinase, myosin heavy chains and magnetic resonance imaging after eccentric exercise. J Sports Sci, 2001; 19(9): 687-91

Speranza L, Grilli A, Patruno A, Franceschelli S, Felzani G, Pesce M, Vinciguerra I, De Lutiis MA, Felaco M. Plasmatic markers of muscular stress in isokinetic exercise. J Biol Regul Homeost Agents, 2007; 21(1-2): 21-9

Spinardi L, Witke W. Gelsolin and diseases. Subcell Biochem, 2007; 45: 55-69

Stäubli M, Roessler B, Köchli HP, Peheim E, Straub PW. Creatine kinase and creatine kinase MB in endurance runners and in patients with myocardial infarction. Eur J Appl Physiol, 1985; 54(1): 40-5

Tiidus PM, Ianuzzo CD. Effects of intensity and duration of muscular exercise on delayed soreness and serum enzyme activities. Med Sci Sports Exerc, 1983; 15(6): 461-5

Váczi M, Costa A, Rácz L, Tihanyi J. Effects of consecutive eccentric training at different range of motion on muscle damage and recovery. Acta Physiol Hung, 2009; 96(4): 459-468

Váczi M, Nagy SA, Kőszegi T, Ambrus M, Bogner P, Perlaki G, Orsi G, Tóth K, Hortobágyi T. Mechanical, hormonal, and hypertrophic adaptations to 10 weeks of eccentric and stretch-shortening cycle exercise training in old males. Exp Gerontol, 2014; 58: 69-77

Van der Meulen JH, Kuipers H, Drukker J. Relationship between exercise-induced muscle damage and enzyme release in rats. J Appl Physiol, 1991; 71(3): 999-1004

Vincent HK, Vincent KR. The effect of training status on the serum creatine kinase response, soreness and muscle function following resistance exercise. Int J Sports Med, 1997; 18: 431-437

Yu CC, Zendzian-Piotrowska M, Charmas M, Dlugolecka B, Baranowski M, Górski J, Bucki R. Change in blood gelsolin concentration in response to physical exercise. Biol Sport, 2013; 30: 169-172

\section{Corresponding author:}

\section{Éva Tékus;}

Institute of Sport Sciences and Physical Education, University of Pécs; Doctoral School of Biology and Sportbiology, University of Pécs, Pécs, Hungary;

Ifjúság Street 6., Pécs, Hungary, H-7624;

Phone number: $+3672 / 503-600$;

Fax number: +3672/501-519;

E-mail address: tekuseva@gamma.ttk.pte.hu 